\title{
Return to sport after hip arthroscopy: are you ready?
}

\author{
Tobias Wörner $^{1,2} \cdot$ Kristian Thorborg $^{3} \cdot$ Kate E. Webster $^{4} \cdot$ Anders Stålman $^{2,5} \cdot$ Frida Eek $^{1}$
}

Received: 7 March 2021 / Accepted: 9 March 2021 / Published online: 31 March 2021

(c) European Society of Sports Traumatology, Knee Surgery, Arthroscopy (ESSKA) 2021

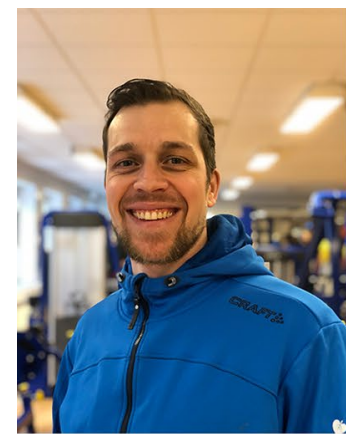

Tobias Wörner

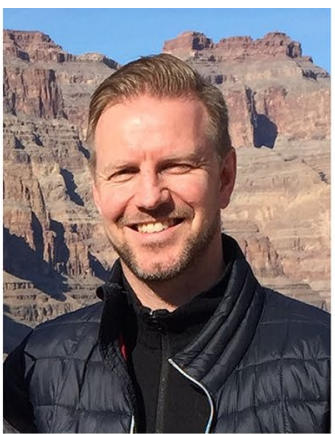

Kristian Thorborg

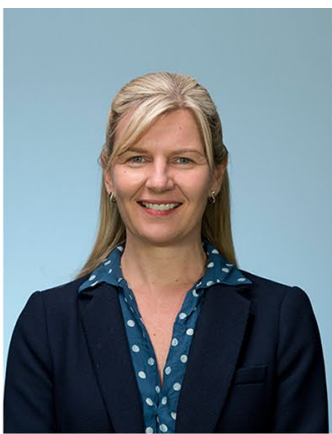

Kate E. Webster

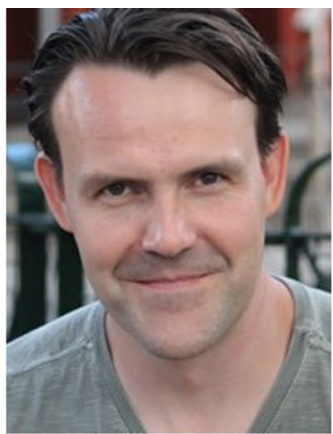

Anders Stålman

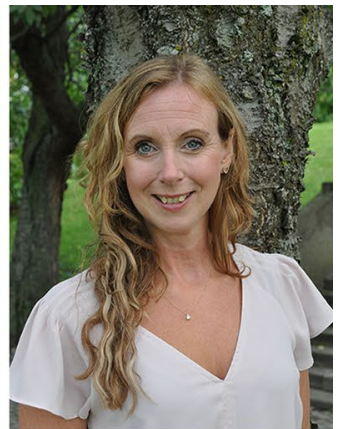

Frida Eek
Return to sport (RTS) is undoubtedly of great importance to many patients. Patients often aim to return to their previous sport following hip arthroscopy, and those who return are most satisfied following surgery and rehabilitation [10]. Unfortunately, only $50 \%$ of patients with femoroacetabular impingement syndrome undergoing hip arthroscopy return to their pre-injury sport, and only 1 in 5 return to their previous level of performance $[4,10]$. In this editorial, we look beyond anatomy and physical recovery following surgery, and consider alternative explanations as to why

Tobias Wörner

Tobias.worner@med.lu.se

1 Department of Health Sciences, Lund University, Box 157, 22100 Lund, Sweden

2 Capio Artro Clinic, FIFA Medical Centre of Excellence, Sophiahemmet Hospital, Stockholm, Sweden

3 Department of Orthopaedic Surgery, Sports Orthopaedic Research Center-Copenhagen (SORC-C), Copenhagen University Hospital, Amager, Hvidovre, Denmark

4 School of Allied Health, Human Services and Sport, La Trobe University, Melbourne, Australia

5 Department of Molecular Medicine and Surgery, Stockholm Sports Trauma Research Center, Karolinska Institutet, Stockholm, Sweden some patients may or may not return to sport following hip arthroscopy - are you ready for it?

\section{A shift from the hip to the head: a missing piece of the puzzle?}

Physical factors, such as injury and deficits, often form the basis of surgical indications. Hip arthroscopy for femoroacetabular impingement syndrome alters hip morphology, reduces or repairs chondrolabral damage, and supposedly improves joint kinematics. Combined with appropriate post-operative rehabilitation, hip arthroscopy reduces pain, symptoms, and improves the way patients perceive their joint health during activities of daily living [3, 6]. However, patient-reported outcome measures show that hip-related function regarding participation in sports and physical activity is often still impaired [7]. Why is that? As clinicians we tend to look to explain these impairments by investigating morphological features or assessing physical function such as range of motion, strength, and functional performance. However, physical factors alone may not explain why so many patients do not RTS following hip arthroscopy. In other orthopedic populations such as ACL reconstructed patients, psychological readiness has been shown to be an important predictor of RTS [2, 9]. Therefore, in our attempt 
to address RTS following hip arthroscopy, we may have to redirect our focus from our arthroscope, dynamometer, or inclinometer to the question: "Are you ready to return to sport?".

\section{How ready are you on a scale from 0 to 100 ?}

Until recently, there has been no existing tool to measure psychological readiness to RTS in hip arthroscopy patients. In this issue of KSSTA you will find the Hip-Return to Sport after Injury scale (Hip-RSI), an item reduced and modified version of the ACL-RSI [8], adapted to hip patients [11]. The Hip-RSI assesses psychological readiness to RTS following hip arthroscopy by asking patients to rate 6 questions about emotions, confidence in performance, and risk appraisal on a $0-100$ visual analogue scale (0 represents extremely negative psychological responses; 100 represents no negative psychological responses). A total score is presented as an average of the individual item scores (Fig. 1).

\section{The RTS puzzle-perhaps not that joint-specific?}

In a cross-sectional comparison, we found progressively higher Hip-RSI-scores among patient groups that have reached higher RTS levels on the RTS continuum [1]. This is interesting as the patients returning to sport performance at the pre-injury level are also the ones most satisfied with their current activity level (Fig. 2).
Psychological readiness to RTS, as measured by the ACLand Hip-RSI, appears to follow the same pattern throughout the RTS-continuum (see Fig. 2) among ACL-reconstructed patients and hip arthroscopy patients [8, 11]. Research on ACL reconstructed patients indicates that psychological recovery (as measured with ACL-RSI) and physiological recovery (joint related physical performance) are two different constructs and should thus be assessed separately in the RTS-process [5]. However, the relationship between physical and psychological function in the RTS process following hip arthroscopy patients is unknown.

\section{The Hip-RSI: a powerful tool!}

With Hip-RSI, we can now measure and follow the development of psychological readiness to RTS in patients who have undergone hip arthroscopy. Unlike the ACL-RSI which has been used for some time, Hip-RSI has only recently been validated for hip arthroscopy patients and thus has not yet been extensively used in clinical research. Our clinical measures of physical function prompt clear clinical approachesimpaired muscle strength can be addressed by strength training, and movement strategies can be modified to avoid pain. However, we do not know how to best address psychological readiness in the RTS process. Therefore, identifying factors that may impact psychological readiness to RTS and developing strategies to address psychological factors alongside functional performance is paramount. We encourage future research to investigate the role of psychological readiness in the RTS process and identify factors that

\section{The Hip-RSI}

1. Do you find it frustrating to have to consider your hip with respect to your sport?

2. Do you feel relaxed about playing your sport?

3. Are you confident that you could play your sport without concern for your hip?

4. Are you confident that you can perform at your previous level of sport participation?

5. Are you confident about your ability to perform well at your sport?

6. Do you think you are likely to reinjure your hip by participating in your sport?

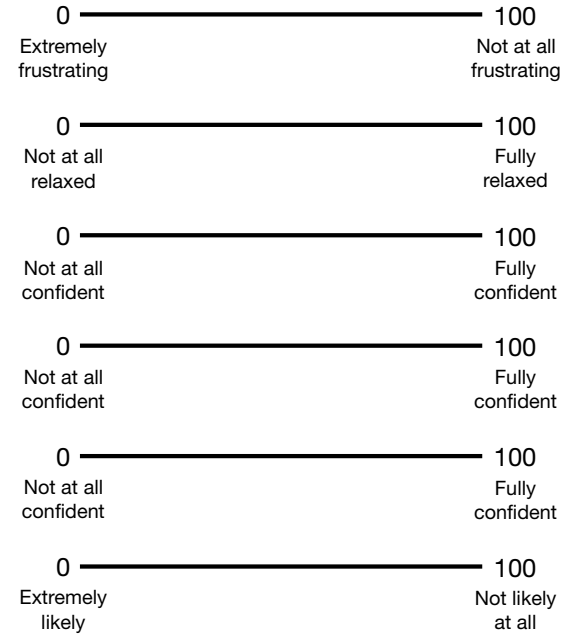


Fig. 2 Psychological readiness to return to sport (Hip-RSI) [11], return to sport rates[10], and satisfaction with the reached level of return to sport [10] (green $=$ satisfied) on the return to sport continuum following hip arthroscopy

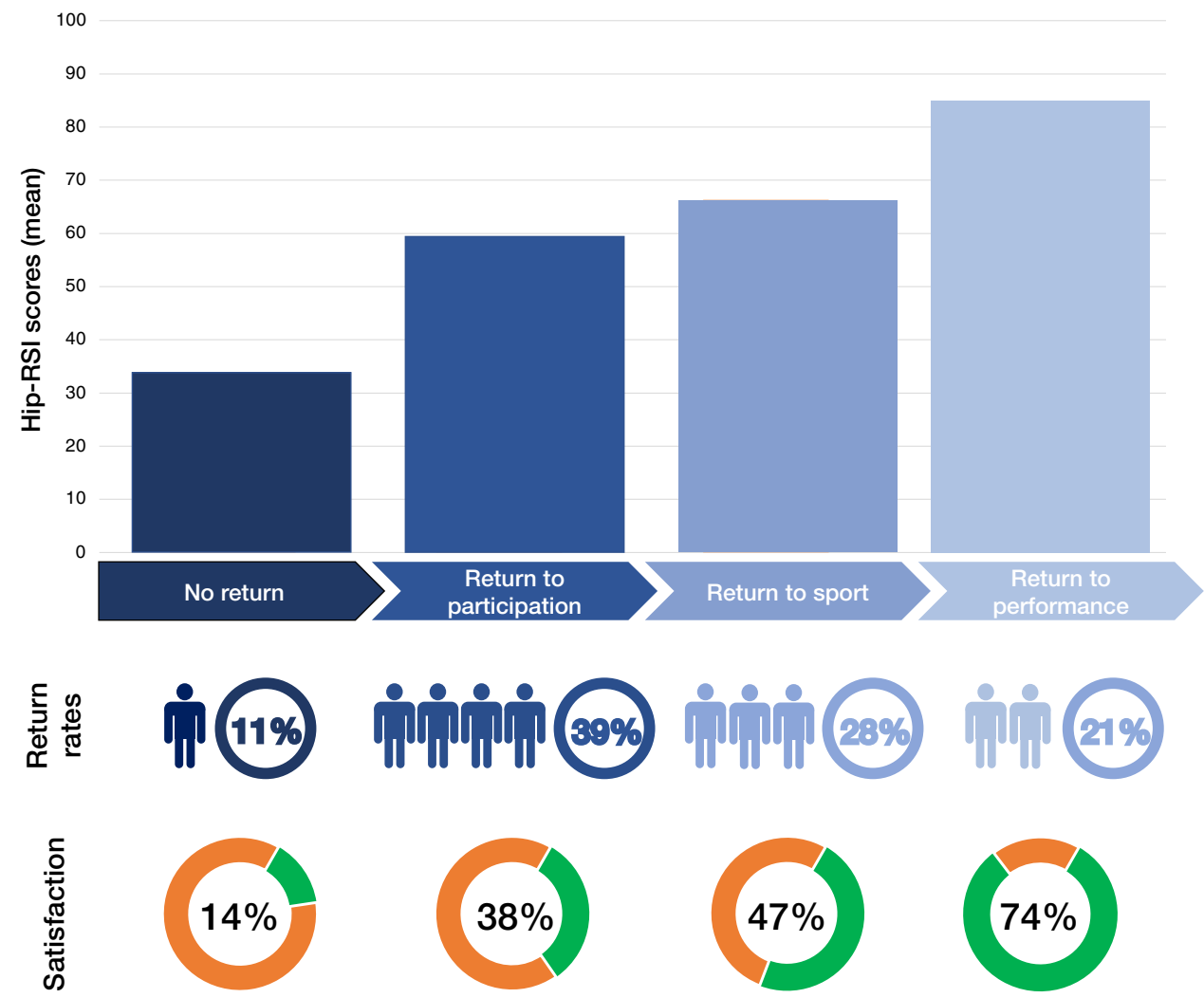

affect psychological readiness. Using measures such as the Hip-RSI provides valuable information about your patient's psychological readiness to RTS and can potentially provide insights regarding previously unexplored aspects of the RTS process following hip arthroscopy. The Hip-RSI can therefore be a powerful tool for all clinicians and researchers working with hip arthroscopy patients-Are you ready to use it?

\section{Acknowledgements None.}

Authors' contribution TW drafted the editorial in collaboration with FE. KT, KEW, and AS read and revised the manuscript.

Funding There is no funding source.

\section{Declarations}

Conflict of interest The authors declare that they have no conflict of interest.

\section{References}

1. Ardern CL, Glasgow P, Schneiders A, Witvrouw E, Clarsen B, Cools A et al (2016) 2016 Consensus statement on return to sport from the First World Congress in Sports Physical Therapy, Bern. Br J Sports Med 50:853-864
2. Faleide AGH, Magnussen LH, Strand T, Bogen BE, Moe-Nilssen $\mathrm{R}$, Mo IF et al (2021) The role of psychological readiness in return to sport assessment after anterior cruciate ligament reconstruction. Am J Sports Med. https://doi.org/10.1177/036354652199192 4363546521991924

3. Griffin DR, Dickenson EJ, Wall PDH, Achana F, Donovan JL, Griffin J et al (2018) Hip arthroscopy versus best conservative care for the treatment of femoroacetabular impingement syndrome (UK FASHIoN): a multicentrerandomised controlled trial. Lancet 391:2225-2235

4. Ishoi L, Thorborg K, Kraemer O, Holmich P (2018) Return to sport and performance after hip arthroscopy for femoroacetabular impingement in 18- to 30-year-old athletes: a cross-sectional cohort study of 189 athletes. Am J Sports Med 46:2578-2587

5. O'Connor RF, King E, Richter C, Webster KE, Falvey EC (2020) No relationship between strength and power scores and anterior cruciate ligament return to sport after injury scale 9 months after anterior cruciate ligament reconstruction. Am J Sports Med 48:78-84

6. Palmer AJR, Ayyar Gupta V, Fernquest S, Rombach I, Dutton SJ, Mansour R et al (2019) Arthroscopic hip surgery compared with physiotherapy and activity modification for the treatment of symptomatic femoroacetabular impingement: multicentrerandomised controlled trial. BMJ 364:1185

7. Thorborg K, Kraemer O, Madsen AD, Holmich P (2018) Patientreported outcomes within the first year after hip arthroscopy and rehabilitation for femoroacetabular impingement and/or labral injury: the difference between getting better and getting back to normal. Am J Sports Med 46(11):2607-2614

8. Webster KE, Feller JA, Lambros C (2008) Development and preliminary validation of a scale to measure the psychological impact of returning to sport following anterior cruciate ligament reconstruction surgery. PhysTher Sport 9:9-15 
9. Webster KE, McPherson AL, Hewett TE, Feller JA (2019) Factors associated with a return to preinjury level of sport performance after anterior cruciate ligament reconstruction surgery. Am J Sports Med 47:2557-2562

10. Worner T, Thorborg K, Stalman A, Webster KE, Momatz Olsson H, Eek F (2018) High or low return to sport rates following hip arthroscopy is a matter of definition? Br J Sports Med 52:1475-1476

11 Worner T, Thorborg K, Webster KE, Stalman A, Eek F (2020) Psychological readiness is related to return to sport following hip arthroscopy and can be assessed by the Hip-Return to Sport after Injury scale (Hip-RSI). Knee Surg Sports TraumatolArthrosc. https://doi.org/10.1007/s00167-020-06157-4

Publisher's Note Springer Nature remains neutral with regard to jurisdictional claims in published maps and institutional affiliations. 